\title{
Long-term risk of endometrial cancer following postmenopausal bleeding and reassuring endometrial biopsy
}

\author{
NICOLE C.M. VISSER ${ }^{1}$, ELLEN M. SPARIDAENS ${ }^{2}$, JAN-WILLEM VAN DEN BRINK ${ }^{3}$, MARIA C. BREIJER ${ }^{4}$, \\ ERIK A. BOSS ${ }^{5}$, SEBASTIAAN VEERSEMA ${ }^{6}$, ALBERT G. SIEBERS ${ }^{1}$, JOHAN BULTEN ${ }^{1}$, \\ JOHANNA M.A. PIJNENBORG ${ }^{7}$ \& RUUD L.M. BEKKERS ${ }^{2}$ \\ ${ }^{1}$ Department of Pathology, Radboud University Medical Center, Nijmegen, ${ }^{2}$ Department of Obstetrics and Gynecology, \\ Radboud University Medical Center, Nijmegen, ${ }^{3}$ Department of Obstetrics and Gynecology, Canisius-Wilhemina Hospital, \\ Nijmegen, ${ }^{4}$ Department of Obstetrics and Gynecology, Erasmus University Medical Center, Rotterdam, ${ }^{5}$ Department of \\ Obstetrics and Gynecology, Máxima Medical Center, Veldhoven, ${ }^{6}$ Department of Obstetrics and Gynecology, St. Antonius \\ Hospital, Nieuwegein, and ${ }^{7}$ Department of Obstetrics and Gynecology, Elisabeth-TweeSteden Hospital, Tilburg, The \\ Netherlands
}

\section{Key words}

Endometrial cancer, endometrial hyperplasia without atypia, endometrial sampling, longterm incidence, postmenopausal bleeding

\section{Correspondence}

Nicole C.M. Visser, Department of Pathology, Radboud University Medical Center, P.O. Box 9101, 6500 HB, Nijmegen, The Netherlands.

E-mail: nicole.visser@radboudumc.nl

\section{Conflict of interest}

The authors have stated explicitly that there are no conflicts of interest in connection with this article.

Please cite this article as: Visser NCM, Sparidaens EM, van den Brink J-W, Breijer MC, Boss EA, Veersema S, et al. Long-term risk of endometrial cancer following postmenopausal bleeding and reassuring endometrial biopsy. Acta Obstet Gynecol Scand 2016; 95:1418-1424.

Received: 14 May 2016

Accepted: 31 August 2016

DOI: 10.1111/aogs.13022

\begin{abstract}
Introduction. Women with postmenopausal bleeding and endometrial thickness $>4 \mathrm{~mm}$ undergo endometrial sampling to exclude endometrial cancer. The aim of this study is to investigate the relative risk of developing endometrial cancer in a prospective cohort after initial work-up for postmenopausal bleeding showing reassuring histology or insufficient sampling. Material and methods. All women presenting with postmenopausal bleeding were prospectively included from January 2009 to April 2011. Follow-up data were collected from patient charts and PALGA (Dutch Pathology Registry). Hazard ratios for endometrial cancer were determined by calculating standardized incidence ratios. Results. A total of 668 women were included and 568 women were available for follow-up [median follow-up time 47 (range 7-63) months]. Women who presented with postmenopausal bleeding, endometrial thickness $>4 \mathrm{~mm}$ and hyperplasia without atypia on biopsy at the first presentation showed a significantly increased risk (standardized incidence ratio 17.15, 95\% confidence interval 1.9661.93) of being diagnosed with endometrial cancer during the first four years of follow up compared with the age-specific population. All women that developed endometrial cancer after initial reassuring histology presented with recurrent postmenopausal bleeding. None of the women with endometrial thickness $>4 \mathrm{~mm}$ and no or insufficient sample for histology at the first presentation developed endometrial cancer during the follow up. Conclusions. Although in general, women with endometrial hyperplasia without atypia are considered to have a low risk for cancer, we observed a significant long-term risk of endometrial cancer after postmenopausal bleeding. Whether additional diagnostics or a more stringent follow-up regimen would be cost-effective, needs to be studied.
\end{abstract}

Abbreviations: BMI, body mass index; SIR, standardized incidence ratio.

\section{Introduction}

Endometrial cancer is the most common gynecologic malignancy in industrialized countries (1). The prevalence of a malignancy of the endometrium among women presenting with postmenopausal bleeding increases with age, from $<1 \%$ of women aged under 50 years up to $24 \%$ of women aged over 80 years (2). International guidelines recommend measurement of the endometrial thickness by 
transvaginal ultrasound in case of postmenopausal bleeding $(3,4)$. In women with an endometrial thickness $\leq 4 \mathrm{~mm}$, there is a very low risk of finding pathological endometrium on biopsy or curettage, therefore refraining from these procedures is considered justified $(4,5)$. In case of an endometrial thickness $>4 \mathrm{~mm}$, outpatient endometrial sampling is indicated to exclude endometrial cancer $(3,4,6)$. When endometrial sampling reveals reassuring histology and hysteroscopic biopsy or saline contrast sonohysterography shows no abnormalities, women are discharged from follow up and instructed to contact the gynecologist in case of recurrent postmenopausal bleeding (4). Although histological finding of endometrial hyperplasia without atypia has a slightly increased risk for developing endometrial cancer, it is generally regarded as reassuring.

In our recently published prospective cohort study we showed that in $74(20.8 \%)$ of 356 women presenting with postmenopausal bleeding and endometrial thickness $>4 \mathrm{~mm}$, outpatient endometrial sampling technically failed, and in $84(29.8 \%)$ the amount of tissue was insufficient for a histopathological diagnosis (7). Currently, there is no consensus on what to do after failure of outpatient endometrial sampling. Some guidelines recommend additional hysteroscopy in all patients, whereas others incorporate risk factors in the decision to obtain histology after first insufficient tissue sample (4,8-10). Previous studies reported (pre)malignancies of the endometrium in up to $20 \%$ of the women after failure of outpatient endometrial sampling (11-14). Despite this knowledge, no further histopathological examination was performed in $45 \%$ of women with an insufficient sample (7). To our knowledge, there are no long-term follow-up studies reporting on the incidence of endometrial cancer after failure of endometrial sampling. We hypothesized an increased risk of endometrial (pre)malignancies in women with postmenopausal bleeding and failure of endometrial sampling.

The aim of this long-term follow-up study was to investigate the relative risk of developing endometrial (pre)malignancies after initial work-up for postmenopausal bleeding showing reassuring histology or insufficient endometrial sampling.

\section{Material and methods}

The current prospective cohort consisted of women presenting with postmenopausal bleeding at TweeSteden Hospital, Tilburg, Máxima Medical Center, Veldhoven and St. Antonius Hospital, Nieuwegein, from January 2009 to April 2011, as previously reported (7). Postmenopausal bleeding was defined as one-time or recurrent vaginal bleeding after a period of at least 12 months of amenorrhea. The diagnostic work-up of all patients was performed in one of the three participating hospitals. According to the guidelines of the Dutch Society of Obstetrics and Gynecology (4), the diagnostic work-up consisted of a double-layer measurement of the endometrium by transvaginal ultrasound and a cervical smear. Women with a first episode of postmenopausal bleeding and an endometrial thickness $\leq 4 \mathrm{~mm}$ were reassured and instructed to contact the gynecologist in case of recurrent postmenopausal bleeding. When endometrial thickness was $>4 \mathrm{~mm}$, not measurable, or in case of persistent or recurrent postmenopausal bleeding, endometrium biopsy was performed using Pipelle endometrial sampling (Pipelle de Cornier, Paris, France) and sent for histological examination. In case of failure of endometrial sampling, repeated endometrial sampling, hysteroscopic biopsy or dilatation and curettage could be performed.

Failure of endometrial sampling was classified as either endometrial sampling that could not be performed (technical failure) or as endometrial sampling in which the procedure was performed but the amount of tissue was insufficient for a reliable histopathological diagnosis (insufficient sampling). Histological diagnosis was made by the pathologists of the participating centers specialized in gynecological pathology. Normal proliferative or atrophic endometrium, and endometrial polyps were considered as benign. Hyperplasia without atypia was, according to the Dutch guidelines, considered a reassuring histology without the need for further follow up, despite a slightly increased risk of endometrial cancer. Both simple atypical hyperplasia and complex atypical hyperplasia were considered premalignancy. According to these guidelines a hysterectomy was recommended for women initially diagnosed with atypical hyperplasia or endometrial cancer.

For this long-term follow-up study, data were collected from the patient charts of the three participating clinics. Follow-up data were evaluated up to March 2014. All consultations for postmenopausal bleeding or possibly related complaints such as an abnormal cervical smear, abdominal pain or an increased abdominal circumference were recorded. The reason for consultation, measurement of the double-layer endometrium by transvaginal ultrasound and the results of diagnostic work-up were reported.

\section{Key Message}

Women with recurrent postmenopausal bleeding have a significant risk of endometrial cancer at follow up despite an initial reassuring histological finding of endometrial hyperplasia without atypia. 
An additional comprehensive search in the nationwide network and registry of histo- and cytopathology in the Netherlands (PALGA) was performed to cross-reference follow-up data. PALGA has reached complete national coverage since 1991 (15). In this way, data from the patient charts could be confirmed and loss from follow up, for example due to moving to another city, was precluded. We registered all (pre)malignant lesions of the uterus and cervix and all ovarian and colorectal cancers during follow up. Discrepancies between data from the patient charts and PALGA were discussed to reach consensus.

No ethical approval was needed for this observational study according to the Code of Conduct for the use of data in Health Research (Dutch Federation of Biomedical Scientific Societies, http://www.federa.org).

\section{Statistical analysis}

Statistical analysis was performed with IBM SPSS Statistics 20.0 (IBM Corporation, Somers, NY, USA). Women were followed from the date of first presentation up to March 2014, or until the diagnosis of endometrial cancer, cervical cancer, ovarian cancer or hysterectomy. The risk of endometrial cancer, relative to the general population, was estimated with standardized incidence ratios (SIRs). The SIR was calculated by dividing the observed incidence by the expected incidence of cancer cases. The expected incidence of cancer was estimated by multiplying the number of person-years with the age-specific incidence rates. The age-specific incidence rates, stratified by five-year age groups, were obtained from the Netherlands Cancer Registry, which is managed by the Netherlands Comprehensive Cancer Organization (IKNL). 95\% Confidence intervals $(\mathrm{CI})$ were calculated.

\section{Results}

A total of 668 women presented with postmenopausal bleeding. At first presentation endometrial thickness was $\leq 4 \mathrm{~mm}$ in $36.7 \%(n=245),>4 \mathrm{~mm}$ in $53.4 \%(n=357)$ and unknown in $9.9 \%(n=66)$. All patient characteristics are summarized in Table 1.

In 73 women, endometrial cancer was diagnosed after work-up at first presentation (10.6\%) (Figure 1). Of these 73 women, 34 had an initial diagnosis based on Pipelle endometrial sampling, 28 on hysteroscopic biopsy, six on dilation and curettage, and in five a hysterectomy was performed without prior histological diagnosis of endometrial cancer or atypical hyperplasia. Most of these women (74.0\%) had an endometrial thickness $>4 \mathrm{~mm}(n=54)$, in $23.3 \%(n=17)$ endometrial thickness was unknown, and in $2.7 \%(n=2)$ endometrial thickness was $\leq 4 \mathrm{~mm}$. Eight women were diagnosed with atypical hyperplasia (1.2\%),
Table 1. Baseline clinical characteristics of the postmenopausal women at first presentation. Values are presented as median (range) or number (\%).

\begin{tabular}{lcc}
\hline $\begin{array}{l}\text { Characteristics of the } \\
\text { women }\end{array}$ & $\begin{array}{c}\text { Total } \\
(n=668)\end{array}$ & $\begin{array}{l}\text { Available for follow up } \\
(n=568)\end{array}$ \\
\hline Age, years & $59(35-93)$ & $58(41-91)$ \\
Body mass index, $\mathrm{kg} / \mathrm{m}^{2}$ & $28(17-77)$ & $28(17-77)$ \\
Time since menopause, & $6(1-50)$ & $5(1-50)$ \\
years & & \\
Endometrial thickness & $245(36.7)$ & $241(42.4)$ \\
$\leq 4$ mm & $357(53.4)$ & $285(50.2)$ \\
$>4$ mm & $66(9.9)$ & $42(7.4)$ \\
Unknown & $50(7.5)$ & $34(6.0)$ \\
Hormone replacement therapy & $518(91.2)$ \\
Yes & $17(90.0)$ & $16(2.8)$ \\
No & $17.5)$ & \\
Unknown & & \\
Hypertension & $230(34.4)$ & $179(31.5)$ \\
Yes & $419(62.7)$ & $371(65.3)$ \\
No & $19(2.8)$ & $18(3.2)$ \\
Unknown & & \\
Diabetes mellitus & $86(12.9)$ & $62(10.9)$ \\
Yes & $562(84.1)$ & $487(85.7)$ \\
No & $20(3.0)$ & $19(3.3)$ \\
Unknown & & \\
\hline
\end{tabular}

four women with cervical cancer $(0.6 \%)$ and one woman with colorectal cancer $(0.1 \%)$. A hysterectomy showing benign histology was performed in 14 women.

A total of 568 women were available for follow up. The median follow-up time was 47 (range 7-63) months. During follow up, eight women were diagnosed with endometrial cancer (1.4\%) (Figure 1). The incidence of endometrial cancer was the highest in the group of women with an endometrial thickness $>4 \mathrm{~mm}$ at first presentation $(n=6 ; 2.1 \%)$. Four women initially had benign endometrial histology obtained by endometrial sampling, hysteroscopic biopsy or curettage and two women hyperplasia without atypia (Figure 2). Their median age of diagnosis was 68 years (range 63-79), and endometrial cancer was diagnosed after a median follow up of 18 months (range 9-24). During follow up these women with a final diagnosis of endometrial cancer presented with recurrent postmenopausal bleeding and underwent endometrial biopsy or curettage in which atypical hyperplasia $(n=2)$ or endometrial cancer $(n=4)$ was diagnosed. Among all women available for follow up $(n=568)$ there was no significant difference in body mass index (BMI), presence of diabetes, hypertension or use of hormone replacement therapy, between women who developed endometrial cancer and those who did not. However, women who developed endometrial cancer were significantly older at first presentation than were women without endometrial cancer $(p=0.002)$, 


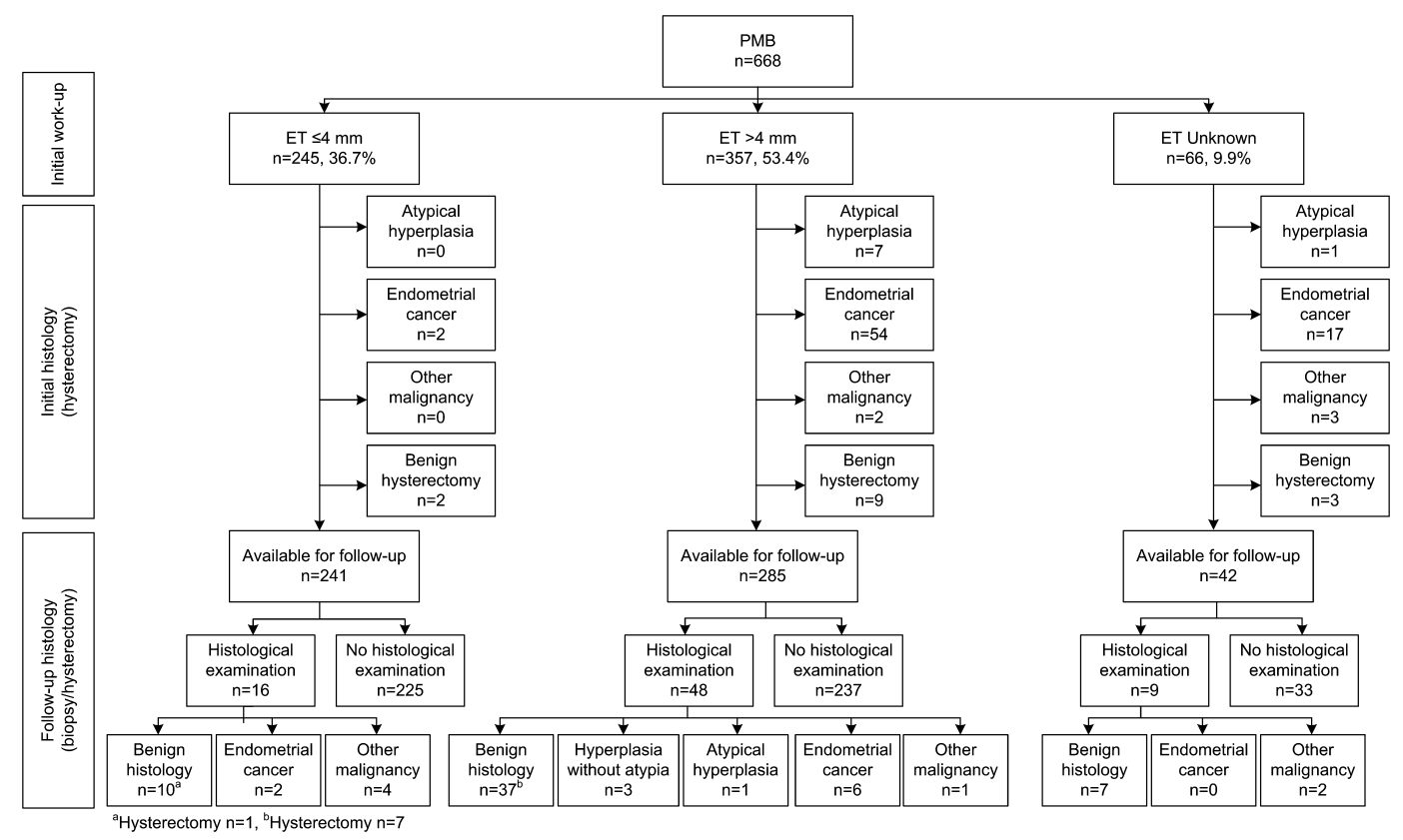

Figure 1. Results of follow up in women presenting with postmenopausal bleeding (PMB) stratified by initial endometrial thickness (ET).

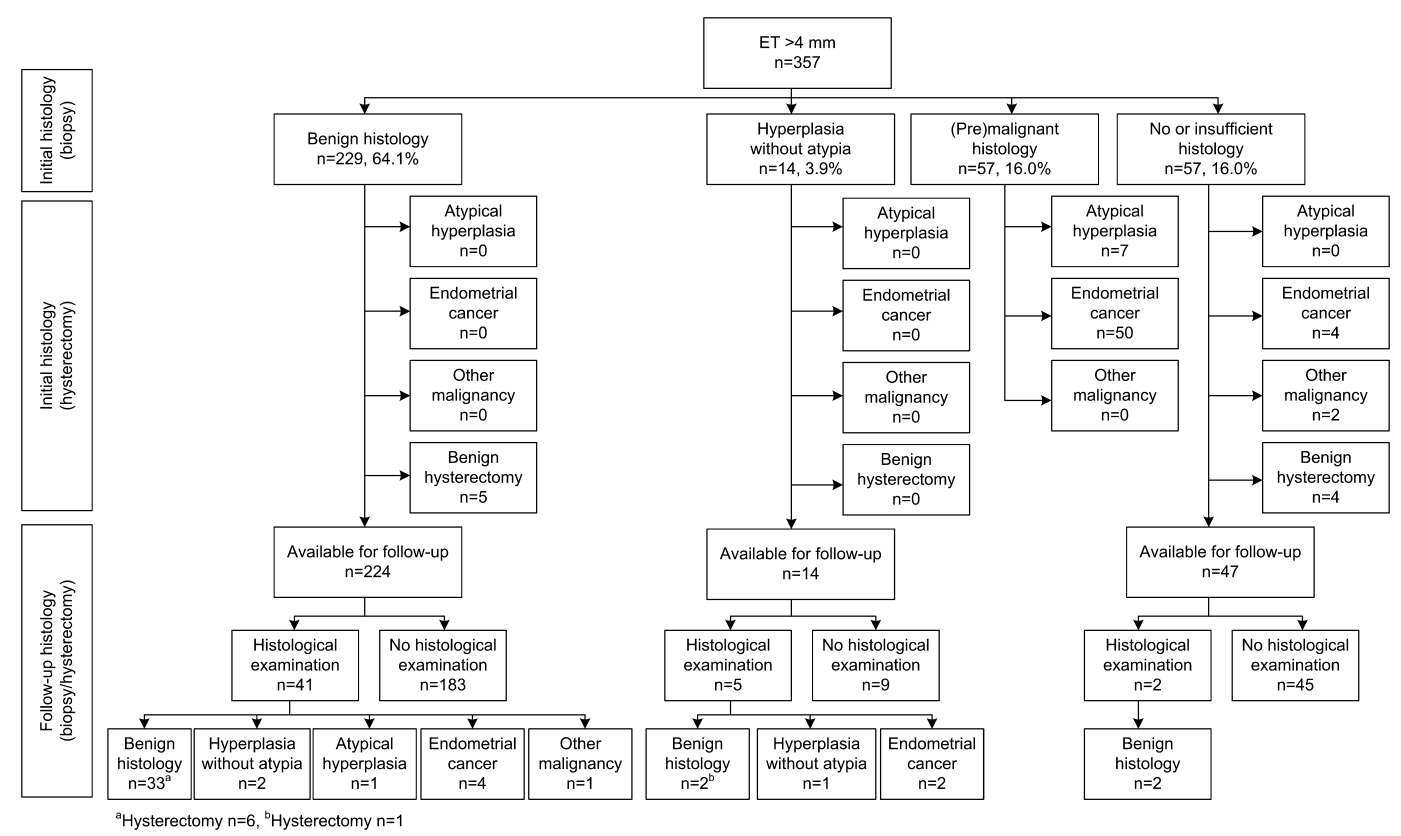

Figure 2. Results of follow up in women presenting with postmenopausal bleeding and initial endometrial thickness (ET) $>4 \mathrm{~mm}$ stratified by initial biopsy results.

median age 68 and 58 years, respectively. This difference in age at first presentation was also seen among women with an initial endometrial thickness $>4 \mathrm{~mm}(p=0.009)$.

Incidence rates found in this study were compared with age-specific incidence rates as reported by the Netherlands Cancer Registry. We found that women who presented with postmenopausal bleeding, an endometrial thickness $>4 \mathrm{~mm}$ and hyperplasia without atypia at first presentation have a 17 times increased risk (SIR 17.15, 95\% CI 1.93-61.93) of developing endometrial cancer during follow up compared with the age-specific population (Table 2). Exclusion of women using hormone 
Table 2. Standardized incidence ratios for women presenting with postmenopausal bleeding.

\begin{tabular}{|c|c|c|c|c|c|c|}
\hline \multirow[b]{2}{*}{ Endometrial thickness } & \multirow[b]{2}{*}{ Initial histology } & \multirow[b]{2}{*}{ Age } & \multirow[b]{2}{*}{$n$} & \multirow[b]{2}{*}{ Person years } & \multicolumn{2}{|c|}{ Endometrial cancer } \\
\hline & & & & & SIR & $95 \% \mathrm{Cl}$ \\
\hline$\leq 4 \mathrm{~mm}$ & All & All & 241 & 959 & 0.90 & $0.10-3.26$ \\
\hline \multirow[t]{3}{*}{$>4 \mathrm{~mm}$} & All & All & 285 & 1112 & 2.34 & $0.85-5.08$ \\
\hline & Benign & All & 224 & 878 & 1.97 & $0.53-5.05$ \\
\hline & $\begin{array}{l}\text { Hyperplasia } \\
\text { without atypia }\end{array}$ & All & 14 & 50 & 17.15 & $1.93-61.93$ \\
\hline Unknown & All & All & 42 & 167 & NA & NA \\
\hline Total & All & All & 568 & 2239 & 1.55 & $0.67-3.05$ \\
\hline
\end{tabular}

SIR, standardized incidence ratio.

replacement therapy did not change conclusions. No endometrial cancer was diagnosed during follow up in women with an endometrial thickness $>4 \mathrm{~mm}$ and no or insufficient histology at first presentation. Although for the whole cohort, women with initial insufficient histology had thinner endometrium than women with sufficient material for diagnosis (median endometrial thickness $5.8 \mathrm{~mm}$ vs. $8.0 \mathrm{~mm}, p<0.001$ ), there was no significant difference in endometrial thickness between these two groups when their endometrial thickness was $>4 \mathrm{~mm}$ (median endometrial thickness $7.4 \mathrm{~mm}$ vs. $9 \mathrm{~mm}, p=0.078)$.

\section{Discussion}

Women presenting with postmenopausal bleeding, endometrial thickness $>4 \mathrm{~mm}$ and hyperplasia without atypia at initial work-up, have a significantly increased risk of developing endometrial cancer during four years of follow up compared with the age-specific population. In contrast to our hypothesis, we did not find endometrial cancer during follow up in women with endometrial thickness $>4 \mathrm{~mm}$ and no or insufficient histology at initial presentation. To our knowledge, this is the first study that identified the incidence of endometrial cancer during long-term follow up stratified by endometrial thickness and histological diagnosis at initial presentation.

The strength of this study is that it is a well-documented, multicenter prospective cohort study, including a large number of women. Loss of follow up was minimized using an additional comprehensive search in PALGA. Incidence rates of endometrial cancer were compared with the age-specific incidence of the Netherland's Cancer Registry, managed by the Netherlands Comprehensive Cancer Organization (IKNL). Still, the number of women in some subgroups during follow up was relatively small, hampering the comparison of different groups. There was no central pathology revision which could both over- or underestimate the incidence of endometrial (pre)malignancies $(16,17)$.
Hyperplasia without atypia,is regarded as reassuring histology due to the small (1-3\%) risk of progression to endometrial cancer (18). As a consequence, follow up of this group of patients is not routinely recommended. Atypical hyperplasia, on the contrary, has a substantial risk of progression to carcinoma ( $8 \%$ of simple atypical hyperplasia, and $29 \%$ of complex atypical hyperplasia) (18). Only a few other studies report on the endometrial cancer risk of endometrial hyperplasias. Lacey et al. observed a relative risk (RR) of 2.0 for simple hyperplasia and 2.8 for complex hyperplasia to progress to endometrial cancer compared with 48 for atypical hyperplasia after one to five years of follow up (19). In our study the risk of endometrial cancer was compared with that in the general population. We observed that women with an endometrial thickness $>4 \mathrm{~mm}$ and hyperplasia without atypia had a 17-fold increased risk compared with the age-specific incidence in the Dutch population.

In our cohort, four of eight cases of endometrial cancer during follow up were diagnosed in women who initially had benign histology. These findings are in line with results of a recent meta-analysis that demonstrated that endometrial sampling is very accurate in diagnosing endometrial cancer, but less accurate in ruling out endometrial cancer (20). A large randomized controlled trial and two retrospective studies have shown that hysteroscopy contributed to the detection of focal (pre)malignancies in women with postmenopausal bleeding and thickened endometrium with benign histology (21-23). In our cohort, 43 women (25.4\%) underwent an additional hysteroscopy with benign histology on Pipelle endometrial sampling, resulting in one patient with endometrial cancer, and three with atypical hyperplasia. These findings are in line with the data of van Hanegem et al. (23) and demonstrate that we might underestimate the risk of (pre)malignancies in women with thickened endometrium that only had Pipelle endometrial sampling. Yet, due to a relatively long follow up of 47 months, it is unlikely that we missed a substantial number of cases with (pre)malignancies. 
We hypothesized that women with postmenopausal bleeding and failure of endometrial sampling were at an increased risk of endometrial (pre)malignancies, but our study could not confirm this. It is remarkable that in $79 \%(45 / 57)$ of the women with initial no, or insufficient, histology and endometrial thickness $>4 \mathrm{~mm}$, no histology was obtained by repeated sampling or hysteroscopic biopsy. There is no consensus in international guidelines on the recommendations after failure of endometrial sampling. Some guidelines recommend standard hysteroscopy with biopsy or curettage in case of failure of outpatient endometrial sampling, whereas others only recommend further investigation in case of risk factors for endometrial cancer or persistent bleeding (11-14). The committee opinion of the American College of Obstetrics and Gynecology recommends transvaginal ultrasound after insufficient sample and further investigation in case of endometrial thickness $>4 \mathrm{~mm}$ (10).

In conclusion, women with initial hyperplasia without atypia seem to have a significantly increased risk of developing endometrial cancer during the first four years of follow up, whereas none of the women with endometrial thickness $>4 \mathrm{~mm}$ and no, or insufficient, histology at first presentation developed endometrial cancer. Although recent studies suggest that further diagnostic work-up in case of benign histology is recommended to exclude focal endometrial (pre)malignancy (20-23), all women in our study that developed endometrial cancer after initial benign histology or hyperplasia without atypia, presented with recurrent postmenopausal bleeding, and were diagnosed with early stage disease. Therefore, based on these data, we cannot yet recommend the need for additional work-up. Whether additional diagnostics or a more stringent follow-up regimen in these women is cost-effective needs to be studied.

\section{Funding}

No specific funding.

\section{References}

1. Siegel R, Ma J, Zou Z, Jemal A. Cancer statistics, 2014. CA Cancer J Clin. 2014;64:9-29.

2. Gredmark T, Kvint S, Havel G, Mattsson LA.

Histopathological findings in women with postmenopausal bleeding. BJOG. 1995;102:133-6.

3. Smith-Bindman R, Kerlikowske K, Feldstein VA, Subak L, Scheidler J, Segal M, et al. Endovaginal ultrasound to exclude endometrial cancer and other endometrial abnormalities. JAMA. 1998;280:1510-7.

4. NVOG (Dutch Society of Obstetrics and Gynaecology). Richtlijn Diagnostiek bij abnormaal vaginaal bloedverlies in de postmenopauze. [Directive Diagnostics in abnormal vaginal bleeding in post-menopause]. (in Dutch). 2015. Available online at: http://nvog-documenten.nl/uploaded/ docs/definitief\%20NVOG\%20richtlijn\%20PMB.pdf (accessed July 25, 2016).

5. Karlsson B, Granberg S, Wikland M, Ylostalo P, Torvid K, Marsal K, et al. Transvaginal ultrasonography of the endometrium in women with postmenopausal bleeding - a Nordic multicenter study. Am J Obstet Gynecol. 1995;172:1488-94.

6. van Hanegem N, Breijer MC, Khan KS, Clark TJ, Burger MP, Mol BW, et al. Diagnostic evaluation of the endometrium in postmenopausal bleeding: an evidencebased approach. Maturitas. 2011;68:155-64.

7. Visser NC, Breijer MC, Herman MC, Bekkers RL, Veersema S, Opmeer BC, et al. Factors attributing to the failure of endometrial sampling in women with postmenopausal bleeding. Acta Obstet Gynecol Scand. 2013;92:1216-22.

8. Cancer Australia. Abnormal vaginal bleeding in pre-, periand post-menopausal women: a diagnostic guide for general practitioners and gynaecologists. 2011. Available online at: https://canceraustralia.gov.au/sites/default/files/ publications/abnormal-vaginal-bleeding-pre-peri-and-postmenopausal-women-diagnostic-guide-general-practitioners/ pdf/ncgc_a3_menopause_chart_june_2012_final.pdf (accessed May 4, 2016).

9. Royal College of Obstetricians \& Gynaecologists (RCOG). Management of endometrial hyperplasia. Green-top Guideline No. 67. 2016. Available online at: https:// www.rcog.org.uk/globalassets/documents/guidelines/greentop-guidelines/gtg_67_endometrial_hyperplasia.pdf (accessed July 25, 2016).

10. American College of Obstetricians and Gynecologists. ACOG Committee Opinion No. 440: The role of transvaginal ultrasonography in the evaluation of postmenopausal bleeding. Obstet Gynecol. 2009;114:409-11.

11. Farrell T, Jones N, Owen P, Baird A. The significance of an 'insufficient' Pipelle sample in the investigation of postmenopausal bleeding. Acta Obstet Gynecol Scand. 1999;78:810-2.

12. van Doorn HC, Opmeer BC, Burger CW, Duk MJ, Kooi GS, Mol BW, et al. Inadequate office endometrial sample requires further evaluation in women with postmenopausal bleeding and abnormal ultrasound results. Int J Gynaecol Obstet. 2007;99:100-4.

13. Feldman S, Shapter A, Welch WR, Berkowitz RS. Twoyear follow-up of 263 patients with post/perimenopausal vaginal bleeding and negative initial biopsy. Gynecol Oncol. 1994;55:56-9.

14. Batool T, Reginald PW, Hughes JH. Outpatient pipelle endometrial biopsy in the investigation of postmenopausal bleeding. BJOG. 1994;101:545-6.

15. Casparie M, Tiebosch AT, Burger G, Blauwgeers H, van de Pol A, van Krieken JH, et al. Pathology databanking and 
biobanking in The Netherlands, a central role for PALGA, the nationwide histopathology and cytopathology data network and archive. Cell Oncol. 2007;29:19-24.

16. Wheeler DT, Bristow RE, Kurman RJ. Histologic alterations in endometrial hyperplasia and welldifferentiated carcinoma treated with progestins. Am J Surg Pathol. 2007;31:988-98.

17. Silverberg SG. Problems in the differential diagnosis of endometrial hyperplasia and carcinoma. Mod Pathol. 2000;13:309-27.

18. Kurman RJ, Kaminski PF, Norris HJ. The behavior of endometrial hyperplasia. A long-term study of 'untreated' hyperplasia in 170 patients. Cancer. 1985;56:403-12.

19. Lacey JV Jr, Ioffe OB, Ronnett BM, Rush BB, Richesson $\mathrm{DA}$, Chatterjee $\mathrm{N}$, et al. Endometrial carcinoma risk among women diagnosed with endometrial hyperplasia: the 34-year experience in a large health plan. Br J Cancer. 2008;98:45-53.
20. van Hanegem N, Prins MM, Bongers MY, Opmeer BC, Sahota DS, Mol BW, et al. The accuracy of endometrial sampling in women with postmenopausal bleeding: a systematic review and meta-analysis. Eur J Obstet Gynecol Reprod Biol. 2016;197:147-55.

21. Seto MT, Ip PP, Ngu SF, Cheung AN, Pun TC. Positive predictive value of endometrial polyps in Pipelle aspiration sampling: a histopathological study of 195 cases. Eur J Obstet Gynecol Reprod Biol. 2016;203:12-5.

22. Svirsky R, Smorgick N, Rozowski U, Sagiv R, Feingold M, Halperin R, et al. Can we rely on blind endometrial biopsy for detection of focal intrauterine pathology? Am J Obstet Gynecol. 2008;199:115.e1-3.

23. van Hanegem N, Breijer MC, Slockers SA, Zafarmand $\mathrm{MH}$, Geomini P, Catshoek R, et al. Diagnostic workup for postmenopausal bleeding: a randomised controlled trial. BJOG. 2016 May 26. doi: 10.1111/1471-0528.14126. [Epub ahead of print]. 